\title{
Realistic Lenalidomide Dose Adjustment Strategy for Transplant-Ineligible Elderly Patients with Relapsed/Refractory Multiple Myeloma: Japanese Real-World Experience
}

\author{
Aya Nakaya Shinya Fujita Atsushi Satake Takahisa Nakanishi \\ Yoshiko Azuma Yukie Tsubokura Masaaki Hotta Hideaki Yoshimura \\ Kazuyoshi Ishii Tomoki Ito Shosaku Nomura \\ First Department of Internal Medicine, Kansai Medical University, Hirakata, Japan
}

\section{Keywords}

Elderly · Lenalidomide · Reduced dose - Relapsed/refractory multiple myeloma $\cdot$ Transplant ineligibility

\begin{abstract}
Lenalidomide is an immunomodulatory drug administered orally in the treatment of multiple myeloma. Some elderly patients require a reduced lenalidomide dose because of comorbidities and/or adverse events. This study investigated the actual dose of lenalidomide in elderly patients, finding that most received reduced (5-10 mg) doses. The most common reasons for dose reduction were renal dysfunction (54\% of patients), fatigue (grade $\geq 3 ; 20 \%$ ), hematologic disorder (grade $\geq 3 ; 14 \%$ ), and rash (grade $\geq 3 ; 9 \%$ ). Their median time to progression was 11.8 months and their median overall survival was 39.2 months. The overall response rate was $73 \%$, including $17 \%$ with a complete response, $19 \%$ with a very good partial response, and $37 \%$ with a partial response. These results showed that, contrary to western countries, most patients were treated with a reduced dose of lenalidomide in Japan. However, it is suggested that continued treatment with a tolerable dose may yield favorable outcomes.
\end{abstract}

(C) 2017 The Author(s)

Published by S. Karger AG, Basel

\section{KARGER}

E-Mail karger@karger.com www.karger.com/aha

This article is licensed under the Creative Commons Attribution-
(C) 2017 The Author(s)

Published by S. Karger AG, Basel

Karger

Open access NonCommercial-NoDerivatives 4.0 International License (CC BYNC-ND) (http://www.karger.com/Services/OpenAccessLicense). Usage and distribution for commercial purposes as well as any distribution of modified material requires written permission.

\section{Introduction}

Lenalidomide is an immunomodulatory drug administered orally in the treatment of multiple myeloma (MM). Generally, lenalidomide treatment yields favorable outcomes, including in elderly patients, especially in the outpatient setting. The recommended dose of lenalidomide is $25 \mathrm{mg} /$ day, but must be reduced in some patients because of comorbidities or adverse events.

Although MM primarily affects elderly individuals, this population is generally underrepresented in clinical trials. Therefore, the appropriate dose of lenalidomide for elderly subjects has not been determined. Palumbo et al. [1] recommended dose reductions according to age and vulnerability using a "frailty scale," but this scale has not been evaluated in various races and is too cumbersome for clinical application. Thus, standard criteria for lenalidomide dose reductions in elderly patients have not yet been determined.

Additionally, because the standard dose of $25 \mathrm{mg} /$ day was formulated for western patients, the suitability of this dose for Japanese individuals, who usually have smaller physiques, is unclear. The Frontline Investigation of Lenalidomide and Dexamethasone versus Standard Thalid-

Aya Nakaya

First Department of Internal Medicine, Kansai Medical University 2-5-1, Shin-machi, Hirakata, Osaka 573-1010 (Japan)

E-Mail nakaya1016@yahoo.co.jp 
Table 1. Patient characteristics

\begin{tabular}{|c|c|}
\hline Patients, $n$ & 56 \\
\hline Median age (range), years & $76.5(67-88)$ \\
\hline Male, $\%$ & 54 \\
\hline \multicolumn{2}{|l|}{ M-protein, \% } \\
\hline IgG & 52 \\
\hline IgA & 30 \\
\hline BJP & 14 \\
\hline $\operatorname{IgD}$ & 4 \\
\hline \multicolumn{2}{|l|}{ ISS, \% } \\
\hline I & 34 \\
\hline II & 32 \\
\hline III & 34 \\
\hline \multicolumn{2}{|l|}{ PS, $\%$} \\
\hline 0 & 7 \\
\hline 1 & 66 \\
\hline $2 \leq$ & 27 \\
\hline \multicolumn{2}{|l|}{ Frequency of CRAB, \% } \\
\hline Hypercalcification & 5 \\
\hline Anemia & 59 \\
\hline Renal failure & 38 \\
\hline Bone disease & 66 \\
\hline On hemolysis dialysis, $\%$ & 5 \\
\hline
\end{tabular}

BJP, Bence-Jones protein; ISS, International Staging System; PS, performance status.

omide (FIRST) clinical trial included patients of various ethnicities, including Asians [2]. However, dose reductions based on body weight or body surface area were not reported. Therefore, patients are treated with the recommended dose of $25 \mathrm{mg} /$ day, without alteration, although dose reductions are allowed to lessen the risk of renal dysfunction. Because this dose will likely be utilized in tests of combinations of lenalidomide with investigative agents, including daratumumab and ixazomib, lenalidomide dose adjustment protocols are both important and necessary.

In our facility (Kansai Medical University Hospital, Osaka, Japan), most elderly MM patients do not receive the recommended dose of lenalidomide because they are more susceptible to adverse events and often unable to tolerate full doses. This study therefore investigated the actual use of lenalidomide in elderly patients and the efficacy of this therapy.

\section{Materials and Methods}

The study included 56 consecutively diagnosed transplant-ineligible patients with relapsed/refractory MM aged $\geq 65$ years who were treated with a lenalidomide plus dexamethasone regimen at Kansai Medical University Hospital from January 2011 to Decem- ber 2015. Patients who had undergone transplantation or had received lenalidomide as an initial treatment were excluded.

During each 28-day treatment cycle, patients received lenalidomide on days 1-21 and dexamethasone (20 or $40 \mathrm{mg}$ ) on days 1,8 , 15 , and 22. The primary endpoint was the time to disease progression (TTP). Secondary end points included overall survival (OS) and the overall response rate (ORR), which was defined as the sum of patients who achieved a complete response (CR), very good partial response (VGPR), and partial response (PR), based on criteria set by the International Myeloma Working Group [3]. The severity of adverse effects was graded using the National Cancer Institute Common Terminology Criteria for Adverse Events v.4.0 [4].

Both TTP and OS were estimated by the Kaplan-Meier method and compared by log-rank tests. Correlations of response with patient characteristics were determined by Spearman correlation analysis. All statistical tests were 2 -sided, statistical significance was set at $p<0.05$, and 95\% confidence intervals were calculated. All statistical analyses were performed using EZR software (Saitama Medical Center, Jichi Medical University, Saitama, Japan), a graphical user interface for R version 2.13.0 (The R Foundation, Austria). More precisely, it is a modified version of R Commander (v.1.6-3) designed to add statistical functions frequently used in biostatistics. This retrospective analysis was approved by the Ethics Committee of Kansai Medical University.

\section{Results}

\section{Patients and Treatment}

The 56 patients included 30 (54\%) men and 26 (46\%) women, of mean age 76.5 years (range 67-88; Table 1 ). The M-protein consisted of IgG in $52 \%$ of patients and IgA in $30 \%$, with Bence-Jones protein detected in $14 \%$. According to the International Scoring System, 34, 32, and $34 \%$ were in stages I-III, respectively. The frequency of CRAB factors were bone disease (66\%), followed by anemia (59\%), renal failure (38\%), and hypercalcemia (5\%). In addition, $5 \%$ of patients were on hemodialysis, and $73 \%$ were treated with lenalidomide as a second-line regimen and $14 \%$ as a third-line regimen. The median treatment period was 9.0 months (range 1.0-60.0) and median follow-up period was 16.0 months (range 1.560.0).

Although the recommended lenalidomide dose is 25 $\mathrm{mg} /$ day, MM patients in our facility are usually started at a reduced dose, at the discretion of each physician, to more closely monitor adverse events, with the dose gradually increased to a continued dose (Fig. 1). However, although doses in most elderly patients are increased, the continued dose is usually below the maximum.

The most common starting dose in our patient cohort was $10 \mathrm{mg} /$ day (45\% of patients), followed by $5 \mathrm{mg} /$ day (21\%), $15 \mathrm{mg} /$ day (20\%), $20 \mathrm{mg} /$ day (4\%), and $25 \mathrm{mg} /$ day (10\%; Table 2). The most common treatment dose (dose
56

Acta Haematol 2017;138:55-60

DOI: $10.1159 / 000477792$
Nakaya et al. 
Fig. 1. The schedule for dose adjustment. Lenalidomide (Len) was started on a minimum dose and gradually increased to the highest dose during days 1-21.

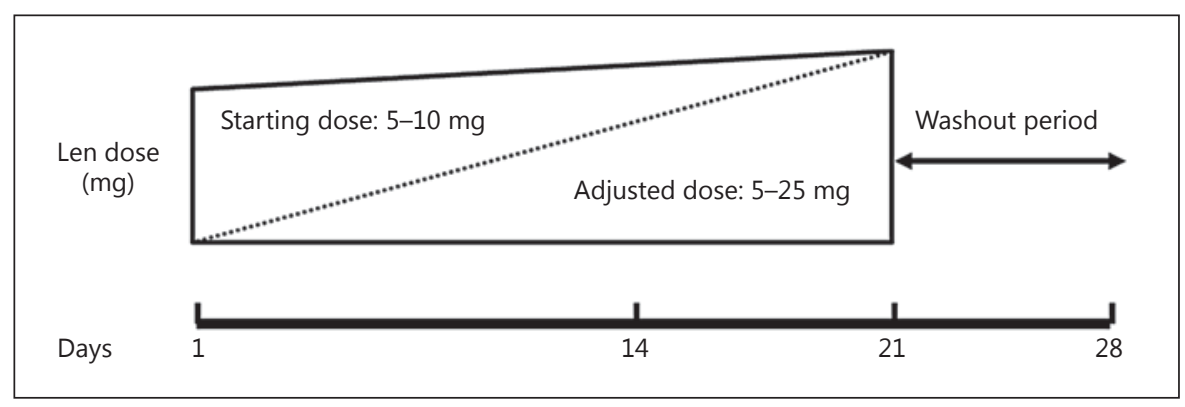

used for the longest period) was $10 \mathrm{mg} /$ day (46\% of patients), followed by $5 \mathrm{mg} /$ day (25\%), $15 \mathrm{mg} /$ day (16\%), 20 $\mathrm{mg} /$ day (4\%), and $25 \mathrm{mg} /$ day (9\%; Table 2). The most frequent reasons for dose reduction were renal dysfunction ( $54 \%$ of patients), fatigue (grade $\geq 3 ; 20 \%$ ), hematologic disorder (grade $\geq 3 ; 14 \%$ ), and rash (grade $\geq 3$; $9 \%$; Table 3).

\section{Efficacy}

The median TTP was 11.8 months (range 8.4-21.9; Fig. 2a), and the median OS was 39.2 months (range 26.6 months to not determined; Fig. 2b). According to the dose, the median TTP of the patients who received a dose of 5-10 mg of lenalidomide was 14.5 months (range 8.421.9), whereas the TTP of patients with lenalidomide at a dose of more than $10 \mathrm{mg}$ was 8.9 months (range 3.7-33.8; $p=0.466$ ). The median OS of the patients who received a dose of 5-10 mg of lenalidomide was 38.9 months (range 25.0-41.7), whereas the median OS of the patients with lenalidomide at a dose of more than $10 \mathrm{mg}$ was not available ( $p=0.275$; data not shown).

The ORR was $73 \%$ (CR in $17 \%$ of patients, VGPR in $19 \%$, and PR in $37 \%$ ). In addition, $23 \%$ of patients had stable disease, with only $4 \%$ showing disease progression (Table 4).

\section{Correlation between Cumulative Doses and Response}

The median cumulative dose was $1,097.5 \mathrm{mg}$ (range $80-9,870)$. The correlation coefficient between cumulative doses and best response was 0.134 ( $p=0.324$; Fig. 3 ).

\section{Development of Malignancies}

Nine patients developed other types of malignancy during treatment with lenalidomide: 2 patients developed lung cancer; 2 developed colon cancer; stomach, pancreas, bladder, and brain cancer each affected 1 patient; and 1 developed a hematological disorder, myelodysplastic syndrome. Two patients stopped lenalidomide because of

Lenalidomide Dose Adjustment Strategy for Elderly MM Patients
Table 2. Comparison of starting and continued doses

\begin{tabular}{rll}
\hline Dose & Starting dose, $\%$ & Continued dose $^{1}, \%$ \\
\hline $5 \mathrm{mg}$ & 21 & 25 \\
$10 \mathrm{mg}$ & 45 & 46 \\
$15 \mathrm{mg}$ & 20 & 16 \\
$20 \mathrm{mg}$ & 4 & 4 \\
$25 \mathrm{mg}$ & 10 & 9 \\
\hline
\end{tabular}

1 The treatment dose used for the longest period.

Table 3. Reasons for reduction

\begin{tabular}{lr}
\hline Renal failure & $54 \%$ \\
Fatigue & $20 \%$ \\
Hematologic disorder & $14 \%$ \\
Rash & $9 \%$ \\
Edema & $1 \%$ \\
Constipation & $1 \%$ \\
Adherence & $1 \%$ \\
\hline
\end{tabular}

the malignancy, whereas the others restarted lenalidomide after surgery. One patient died of the second malignancy.

\section{Discussion}

Until December 2015, only bortezomib and conventional agents could be used in the initial treatment of myeloma in Japan. At that time, lenalidomide was permitted for use in relapsed/refractory myeloma patients. Lenalidomide is taken orally, thus it is a convenient agent and used widely for elderly patients. Although treatment of elderly patients with the recommended dose of lenalidomide is difficult and tends to lead to severe adverse events, no con-

Acta Haematol 2017;138:55-60 57 


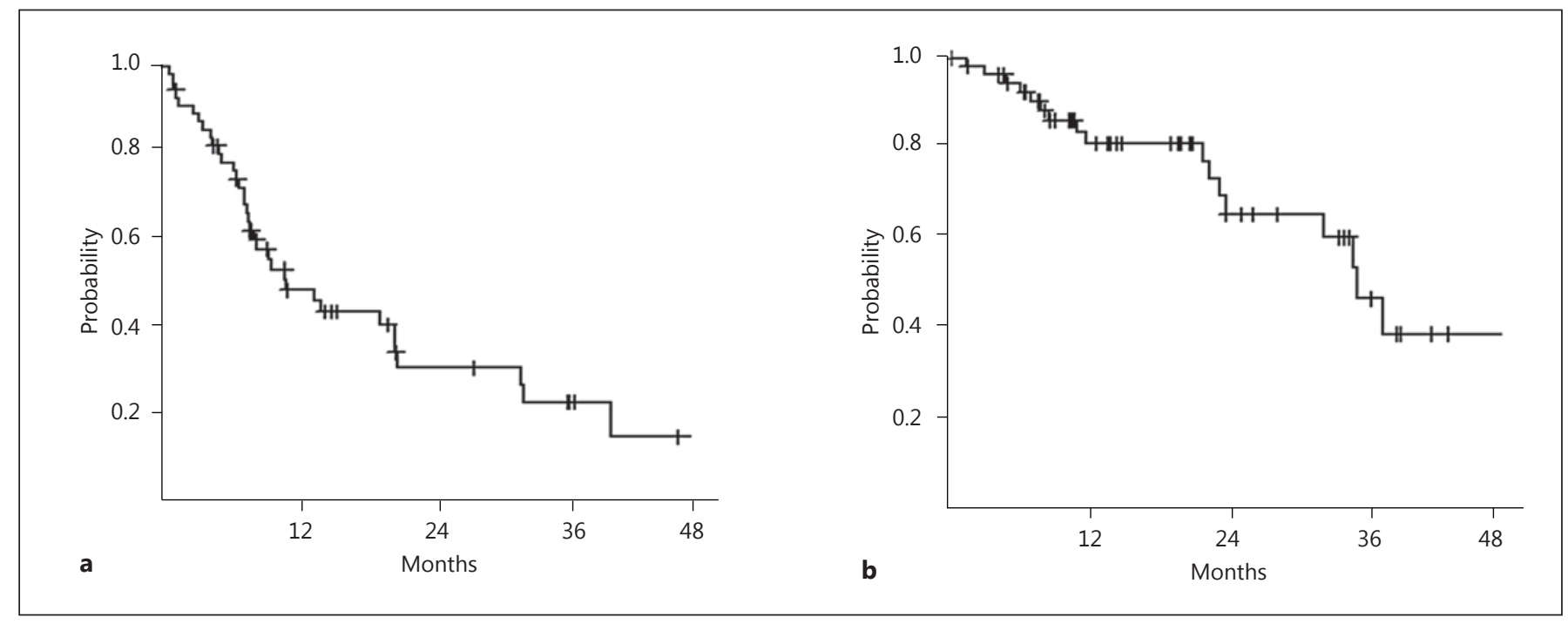

Fig. 2. a The median TTP was 11.8 months (range 8.4-21.9). b The median OS was 39.2 months (range 26.6 to not determined). Lenalidomide was started on a minimum dose and gradually increased to the highest dose during days $1-14$.

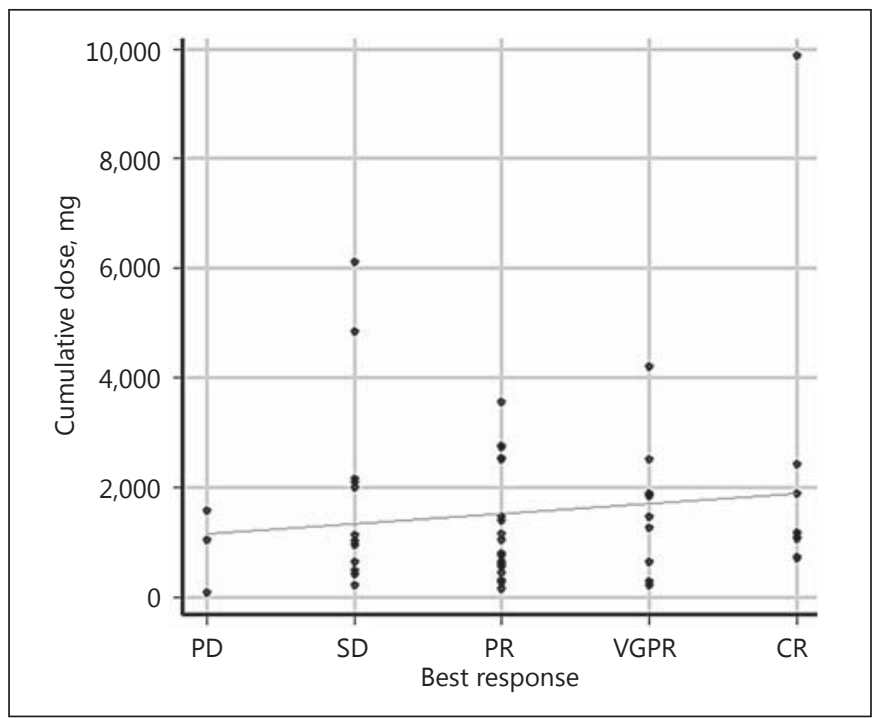

Fig. 3. Correlation between cumulative doses and best response. The median cumulative dose was $1,097.5 \mathrm{mg}$ (range $80-9,870$ ). The correlation coefficient between cumulative dose and best response was $0.134(p=0.324)$. CR, complete response; VGPR, very good partial response; $\mathrm{PR}$, partial response; $\mathrm{SD}$, stable disease; $\mathrm{PD}$, progressive disease.

sensus has been reached on dose reduction. Only a few reports to date have described the effects of lenalidomide dose reductions. In one study, 150 elderly ( $>60$ years) patients with relapsed/refractory MM were treated with 15 $\mathrm{mg} /$ day of lenalidomide plus dexamethasone [5]. This re-
Table 4. Response rate

$\begin{array}{lr}\text { Complete response } & 17 \% \\ \text { Very good partial response } & 19 \% \\ \text { Partial response } & 37 \% \\ \text { Stable disease } & 23 \% \\ \text { Progressive disease } & 4 \%\end{array}$

duced dose of lenalidomide was effective (ORR 69\%), while being less toxic, in elderly patients. Other studies have reported that 10 or $15 \mathrm{mg} /$ day of lenalidomide was safe with a reasonable response in 19 patients with relapsed/refractory MM [6], and that $5 \mathrm{mg} /$ day of lenalidomide was safe and effective in 6 patients with MM [7].

Although most patients in the present study were treated with only $5-10 \mathrm{mg} /$ day of lenalidomide, they showed a high ORR (73\%), similar to the results of the FIRST trial [2]. In 2 large phase 3 trials, MM-009 [8] and MM-010 [9], the median TTPs were 11.1 and 11.3 months, respectively, and the ORRs were 61.0 and $60.2 \%$, respectively. Dose reductions were required in $76.8 \%$ of patients in MM-009 and 76.1\% in MM-010, with 19.8 and 8.8\%, respectively, discontinuing because of adverse events.

Although the recommended initial dose of lenalidomide is $25 \mathrm{mg}$ /day, we started patients on a reduced dose, increasing it gradually while monitoring carefully for adverse events. We think that this strategy is sensible as we did not have to stop treatment because of adverse events.
58

Acta Haematol 2017;138:55-60 DOI: $10.1159 / 000477792$
Nakaya et al. 
Evidence is emerging that continuous treatment can improve progression-free survival and OS [10].

Lenalidomide has been postulated to have 2 main mechanisms of action: cytotoxicity and immunoregulation. Neither mechanism is understood clearly. Basic science studies have suggested that a high dose of lenalidomide ( $25 \mathrm{mg} /$ day) elicits cytotoxic effects, whereas a low dose of lenalidomide (5-15 mg/day) activates antitumor immunity $[11,12]$. OS in the present study was 39.2 months, which is better than that of large phase 3 trials (MM-009) [8]. OS in MM-009 was 29.6 months. The difference in this result might be due to the immune effect of low-dose lenalidomide.

Although we observed a positive correlation between the cumulative dose of lenalidomide and patient response, this correlation was not statistically significant. However, this study may have included too few patients to reveal a correlation. Our findings suggest, however, that treatment with lenalidomide for long periods of time, even in small doses, may yield favorable outcomes. This result might also result from the immune effect of lowdose lenalidomide. Of course, the relationship between lenalidomide dose and its efficacy should be proven by the measurement of blood concentration of lenalidomide in the future.

Of the 56 patients in our cohort, 9 (16\%) developed other malignancies during lenalidomide treatment. Al- though this rate is higher than normal, it is uncertain whether it is related to lenalidomide or the original nature of myeloma [10,13].

This study had 2 major limitations. First, this was a retrospective, single-institution study with a short followup and small number of patients. Second, although genetic and biologic backgrounds can affect the efficacy of lenalidomide, we could not perform detailed genetic tests because of limitations in patient insurance policies.

The aim of MM treatment in elderly patients is to maintain a good quality of life. Overly aggressive therapy may result in treatment discontinuation. Because treatment maintenance may be more important for favorable outcomes, tolerable doses of lenalidomide may be the best treatment strategy for elderly patients with MM.

In conclusion, our findings suggest that transplant-ineligible elderly patients with MM be started on a minimum dose of lenalidomide, with the dose being gradually increased to the highest possible (maximum dose, $25 \mathrm{mg}$ / day), and that these patients be maintained on a tolerable dose for as long as possible.

\section{Disclosure Statement}

All authors declare there are no competing financial interests in relation to this work.

\section{References}

1 Palumbo A, Bringhen S, Mateos MV, Larocca A, Facon T, Kumar SK, Offidani M, McCarthy P, Evangelista A, Lonial S, Zweegman S, Musto P, Terpos E, Belch A, Hajek R, Ludwig $\mathrm{H}$, Stewart AK, Moreau P, Anderson K, Einsele H, Durie BG, Dimopoulos MA, Landgren O, San Miguel JF, Richardson P, Sonneveld P, Rajkumar SV: Geriatric assessment predicts survival and toxicities in elderly myeloma patients: an International Myeloma Working Group report. Blood 2015;125:2068-2074.

2 Benboubker L, Dimopoulos MA, Dispenzieri A, Catalano J, Belch AR, Cavo M, Pinto A, Weisel K, Ludwig H, Bahlis N, Banos A, Tiab M, Delforge M, Cavenagh J, Geraldes C, Lee JJ, Chen C, Oriol A, de la Rubia J, Qiu L, White DJ, Binder D, Anderson K, Fermand JP, Moreau P, Attal M, Knight R, Chen G, van Oostendorp J, Jacques C, Ervin-Haynes A, Avet-Loiseau H, Hulin C, Facon T; FIRST Trial Team: Lenalidomide and dexamethasone in transplant-ineligible patients with myeloma. N Engl J Med 2014;371:906-917.

Lenalidomide Dose Adjustment Strategy for Elderly MM Patients
3 Durie BG, Harousseau JL, Miguel JS, Bladé J, Barlogie B, Anderson K, Gertz M, Dimopoulos M, Westin J, Sonneveld P, Ludwig H, Gahrton G, Beksac M, Crowley J, Belch A, Boccadaro M, Cavo M, Turesson I, Joshua D, Vesole D, Kyle R, Alexanian R, Tricot G, Attal M, Merlini G, Powles R, Richardson P, Shimizu K, Tosi P, Morgan G, Rajkumar SV; International Myeloma Working Group: International uniform response criteria for multiple myeloma. Leukemia 2006;20:1467-1473.

4 National Cancer Institute: CTEP: Cancer Therapy Evaluation Program. http://ctep. cancer.gov/protocolDevelopment/electronic_applications/ctc.htm\#ctc_40.

5 Quach H, Harrison S, Fernyhough L, Henderson R, Corbett G, Baker B, Browett P, Blacklock H, Forsyth C, Underhill C, Cannell P, Trotman J, Neylon A, Link E, Li JS, Dimopoulos MA, Prince HM: Lower dose lenalidomide-dexamethasone is less toxic and does not compromise efficacy for patients with relapsed/refractory multiple myeloma who are aged $\geq 60$ years and/or with renal impairment and/or with thrombocytopenia. Clin Lymphoma Myeloma Leuk 2015;15(suppl 3):e284-e285.

6 Yamasaki H, Hata H: Low dose lenalidomide treatment trial for multiple myeloma: SAKURA study in Kumamoto. Rinsho Ketsueki 2011;52:1163.

7 Minagawa K, Kawano H, Suzuki T, Inagaki T, Kishi M, Hirata T, Kimura S, Takechi M, Koide T, Iwai M, Katayama Y, Matsui T: Very low-dose lenalidomide therapy for elderly multiple myeloma patients. Rinsho Ketsueki 2013;54:457-462.

8 Palumbo A, Hajek R, Delforge M, Kropff M, Petrucci MT, Catalano J, Gisslinger $\mathrm{H}$, Wiktor-Jędrzejczak W, Zodelava M, Weisel K, Cascavilla N, Iosava G, Cavo M, Kloczko J, Bladé J, Beksac M, Spicka I, Plesner T, Radke J, Langer C, Ben Yehuda D, Corso A, Herbein L, Yu Z, Mei J, Jacques C, Dimopoulos MA; MM-015 Investigators: Continuous lenalidomide treatment for newly diagnosed multiple myeloma. N Engl J Med 2012;366:1759-1769. 
9 Weber DM, Chen C, Niesvizky R, Wang M, Belch A, Stadtmauer EA, Siegel D, Borrello I, Rajkumar SV, Chanan-Khan AA, Lonial S, Yu Z, Patin J, Olesnyckyj M, Zeldis JB, Knight RD; Multiple Myeloma (009) Study Investigators: Lenalidomide plus dexamethasone for relapsed multiple myeloma in North America. N Engl J Med 2007;357:2133-2142.

10 Jones JR, Cairns DA, Gregory WM, Collett C, Pawlyn C, Sigsworth R, Striha A, Henderson R, Kaiser MF, Jenner M, Cook G, Russell NH, Williams C, Pratt G, Kishore B, Lindsay J, Drayson MT, Davies FE, Boyd KD, Owen RG,
Jackson GH, Morgan GJ: Second malignancies in the context of lenalidomide treatment: an analysis of 2,732 myeloma patients enrolled to the Myeloma XI trial. Blood Cancer J 2016;6:e506.

11 Davies F, Baz R: Lenalidomide mode of action: linking bench and clinical findings. Blood Rev 2010;24(suppl 1):S13-S19.

12 Dimopoulos MA, Hussein M, Swern AS, Weber D: Impact of lenalidomide dose on progression-free survival in patients with relapsed or refractory multiple myeloma. Leukemia 2011;25:1620-1626.
13 Musto P, Anderson KC, Attal M, Richardson PG, Badros A, Hou J, Comenzo R, Du J, Durie BGM, San Miguel J, Einsele H, Chen WM, Garderet L, Pietrantuono G, Hillengass J, Kyle RA, Moreau P, Lahuerta JJ, Landgren O, Ludwig $\mathrm{H}$, Larocca A, Mahindra A, Cavo M, Mazumder A, McCarthy PL, Nouel A, Rajkumar SV, Reiman A, Serra ER, Sezer O, Terpos E, Turesson I, Usmani S, Weiss BM, Palumbo A; International Myeloma Working Group: Second primary malignancies in multiple myeloma: an overview and IMWG consensus. Ann Oncol 2017;28:228-245. 